\title{
Diagnostic Delay and Associated Clinical Features of Tuberculosis among Adult Patients with Acute Myeloid Leukemia in Doha, Qatar
}

\author{
Halima El Omri ${ }^{*}$, Ruba Taha1, Wanis Ibrahim², Nancy Kassem³, Lajos Szabados4, \\ Hesham El Sabah', Fatma Ben Abid5, Amna Gamiel1, Aisha Al Khinji1, Wojciech Szmeigielski6, \\ Saba Hasan1, Ibrahim Al Hijji1
}

\author{
${ }^{1}$ Hematology and Medical Oncology, Hamad Medical Corporation, Doha, Qatar \\ ${ }^{2}$ Internal Medicine, Hamad Medical Corporation, Doha, Qatar \\ ${ }^{3}$ Clinical Pharmacy, NCCCR, Hamad Medical Corporation, Doha, Qatar \\ ${ }^{4}$ Nuclear Medicine and PET-CT, Hamad Medical Corporation, Doha, Qatar \\ ${ }^{5}$ Infection Disease, Hamad Medical Corporation, Doha, Qatar \\ ${ }^{6}$ Radiology NCCCR Hamad Medical Corporation, Doha, Qatar \\ Email: *HELOMRI@hamad.qa
}

How to cite this paper: El Omri, H., Taha, R., Ibrahim, W., Kassem, N., Szabados, L., El Sabah, H., Abid, F.B., Gamiel, A., Al Khinji, A., Szmeigielski, W., Hasan, S. and Al Hijji, I. (2018) Diagnostic Delay and Associated Clinical Features of Tuberculosis among Adult Patients with Acute Myeloid Leukemia in Doha, Qatar. Journal of Tuberculosis Research, 6, 49-62. https://doi.org/10.4236/jtr.2018.61005

Received: February 13, 2018

Accepted: March 13, 2018

Published: March 16, 2018

Copyright ( 92018 by authors and Scientific Research Publishing Inc. This work is licensed under the Creative Commons Attribution International License (CC BY 4.0).

http://creativecommons.org/licenses/by/4.0/

(c) (i) Open Access

\begin{abstract}
Background: Tuberculosis is currently the world's leading cause of death arising from a single infectious condition. While $\mathrm{T}$ cell mediated immunity is recognized to have a major contribution to tuberculosis activation, the present investigation confirmed that $\mathrm{TB}$ was more prevalent among patients with acute myeloid rather than lymphoid leukemia and such association was frequently overlooked. The primary objective of this study is to estimate the diagnostic delay of tuberculosis among patients with acute myeloid leukemia (AML) and compare it to the general population in Qatar. Secondary objective is to study the clinical and epidemiologic characteristics of tuberculosis in patients with AML. Methods: This is a retrospective study of tuberculosis cases diagnosed in subjects with AML during the period from January 2008 till December 2016. Results: Among 215 subjects with AML identified during the study period, 12 (5.58\%) received the diagnosis of tuberculosis. The estimated incidence of tuberculosis among AML cases was 7.14 cases per 1000 per year. The mean delay in diagnosis of tuberculosis was 64.2 days (95\% CI: 26.8 101.5) and the median was 45 days (interquartile range; Q1 - Q3, 29.5 - 97.5). Prolonged fever was the most common presentation (100\% of cases). Parenchymal lung involvement was the most common radiologic abnormality (83.3\% of cases). Three patients (25\%) died and 8 patients completed 9 to 12 months of anti-tuberculous treatment with clinical and radiological remission. Conclusion: Infections caused by Mycobacterium tuberculosis are not
\end{abstract}


uncommon in patients with AML especially in patients from tuberculosis endemic regions. It constitutes a diagnostic challenge so high index of suspicion is of paramount importance.

\section{Keywords}

Tuberculosis, Acute Myeloid Leukemia, Neutropenia

\section{Introduction}

Tuberculosis (TB) is known to be one of the deadliest diseases of mankind, posing a major burden on global health phenomena, primarily in the low and middle income countries [1] [2]. TB is one of the first and most studied infectious disease, as evident from the contributions of Robert Koch more than 100 years ago.

Evolution: TB is caused by members of the specie Mycobacterium tuberculosis complex (MTBC), which includes: Mycobacterium tuberculosis (Mtb), the etiologic agent of TB in humans; $M$. africanum, that causes TB in humans only in certain regions of Africa; M. bovis, M. caprae and M. pinnipedii, causing TB in wild and domesticated mammals; M. microti, that causes TB only in voles. The World Health Organization (WHO) has estimated that one-third of the total world population is latently infected with M. tuberculosis and 5\% - 10\% of the infected individuals will develop active TB during their life time [3] [4]. However, the risk of developing active disease is $5 \%-15 \%$ every year and lifetime risk is $\sim 50 \%$ in HIV co-infected individuals [4] [5]. Most of the active disease cases in low TB incidence countries arise from this pool of latently infected individuals. The highest incidence rate (363 per 100,000 population) was recorded for the African region, mainly due to high prevalence of HIV infection. The six most populous countries of Asia (China, India, Indonesia, Pakistan, Bangladesh, and Philippines) accounted for $>50 \%$ of all TB cases worldwide. An estimated 1.37 million (15\%) of incident TB cases in 2007 were co-infected with HIV. Nearly $80 \%$ of the HIV-infected TB patients were living in the African region [4]. Globally, 13.7 million total prevalent TB cases were recorded in 2007 corresponding to 206 cases per 100,000 population that resulted in 1.756 million deaths (including 456,000 among TB patients co-infected with HIV) [4].

Tuberculosis can precede or occurs simultaneously or during treatment of HM (Haematological malignancies) [6]. The timing of TB reactivation or development in patients with HM is not clear. Reactivation could result from impaired immunity by underlying HM and/or chemotherapy induced immunosuppression. Patients with HM have an underlying immunological deficiency that facilitates the emergence of infections [7]. Alteration of T-helper (Th1) cell response of the hemopathy itself or that caused by anti-neoplastic chemotherapy or hematopoietic stem cells transplantation (frequently associated to administration of high doses of corticosteroids) lead to an impaired immune response that 
particularly promote the progression from latent to active TB. The risk of developing $\mathrm{TB}$ varies and depending on the type of $\mathrm{HM}$.

The high incidence of TB in AML (Acute Myeloid Leukemia) was explained by alteration of neutrophil function and neutropenia [8] [9] [10]. Neutrophils are the critical components of innate immunity being the most abundant immune cells in the circulation; they provide immune protection against invading pathogens but can also promote certain inflammatory diseases [10] [11]. The neutrophils play integral part in defense mechanism against TB. The estimated prevalence of TB in AL (Acute Myeloid Leukemia) varies between 3 - 4/1000 new cases, in western countries [12] [13], to $22-69$ per 1000 in India [14] [15] [16] [17].

\section{Latent Tuberculosis Infection}

Latent tuberculosis infection (LTBI) in which the tubercle bacillus resists the bactericidal mechanisms of alveolar macrophages, without causing the disease [18] [19]. In this situation, the immune response is able to contain the bacillus, but not to eliminate it. The aim of diagnosing LTBI in patients with HM is the early detection of infection by $M$. tuberculosis while still in the latent phase, so treatment can be undertaken that eliminates the bacillus before the immune conditions deteriorate and the risk of $\mathrm{TB}$ reactivation increases.

Currently, there are three commercial diagnostic tests for LTBI: the Tuberculin Skin Test (TST), which for decades was the only method for detecting TB infection, and two techniques introduced relatively recently that are based on the detection of interferon-gamma (IFN-G) released from sensitized lymphocytes against specific antigens of $M$. tuberculosis: Quantiferon ${ }^{\circledR}-\mathrm{TB}$ Gold in-Tube (QFT) and T-SPOT®.TB (T-SPOT). These are all indirect methods of measuring infection by $M$. tuberculosis, as they detect the existence of an immune response against the bacillus as a surrogate marker of infection [20].

$\mathrm{TB}$ remains a common healthcare problem in the state of Qatar with an estimated incidence rate of 41/100,000 inhabitant as reported in 2012, majority of them are non-Qatari and represents the labor force coming from eastern Asian countries [21]. The following table (Table 1) gives a brief overview of incidence and prevalence of TB in different countries, as per studies undertaken earlier:

The primary objective of this study was to estimate the diagnostic delay of TB among adult patients with acute myeloid leukemia (AML) and to compare it with that of general population of Qatar. The secondary objective was to study the clinical and epidemiologic characteristics of TB in patients with AML.

\section{Patients and Methods}

All cases of leukemia in Qatar are managed at the National Center for Cancer Care and Research (NCCCR). In the present study, we retrospectively reviewed the clinical records of all patients with acute leukemia (AL) registered in NCCCR from January 2008 till December 2016. 215 patients with AML and 126 
Table 1. Studies that have evaluated the risk of tuberculosis in patients with haematological malignancies.

\begin{tabular}{cccc}
\hline Reference & Setting & RR & Comments \\
\hline Libshitz HI [22] & USA & 9.0 & Cancer patients (including HM) \\
de la Cámara [23] & Spain & 2.95 & Allogenic Stem Cell Transplantation \\
Kamboj M [24] & USA & 40 & Highest rate among Stem Cell Transplant Recipients \\
Mishra P [14] & India & 23 & Patients with acute leukemia. Highest rate in AML \\
Stefan DC [25] & South Africa & 22 & Children with LLA \\
Chen CY [26] & Taiwan & 2.05 & Non-Hodgkin Lymphomas and Leukaemias \\
Wu CY [27] & Taiwan & $3.22^{*}$ &
\end{tabular}

RR: Relative Risk compared to the general population. AML: Acute Myeloid Leukemia. HM: Haematological Malignancies. *: Hazard Ratio.

patients with acute lymphoblastic leukemia (ALL) were identified. Each patient with AL had a baseline laboratory examination in addition to the extended leukemia workup that included blood, stool, urine cultures, oropharynx swab, hepatitis B, C, HIV serology, Aspergillus antigen, Quantiferon ${ }^{\circledR}-$ TB Gold In-Tube, chest X-ray and ultrasound (US) examination of abdomen and pelvis.

For patient with AML and TB, plain chest radiography and contrast enhanced computed tomography (CT) scan of the chest; abdomen and pelvis were performed for all patients, magnetic resonance imaging (MRI) for 1 patient, [Fluoro-18]-Fluoro-2-deoxy-D-glucose (18F-FDG) PET integrated with computed tomography (PET CT) for 4 patients at admission. The radiological findings related to TB infection were reviewed by 2 radiologists at diagnosis and follow up.

Statistical analysis: Qualitative and quantitative data values were expressed as frequency along with percentage and mean \pm standard deviation with median. Descriptive statistics were used to summarize demographic and all other clinical characteristics of the participants. The mean delay with $95 \%$ confidence interval (CI) and the median delay with interquartile range (Q1 - Q3) were calculated. All statistical analyses were done using Statistical Packages SPSS-22 (SPSS Inc., Chicago, IL, USA).

\section{Results}

In the present investigation, the estimated incidence of $\mathrm{TB}$ in AML was found to be around 7.14 cases per 1000 per year, as compared to reports of 2012, where an estimated incidence rate of TB was calculated as 41/100,000 inhabitants. Majority of patients represent the Non Qatari labor force coming from east Asian countries [21], as clearly indicated in the present study, as per patient demographic details (Table 2). Case detection rate in the National Reference Laboratory in Qatar, as per National TB program exceeds $70 \%$. The incidence of TB in our study was $5.58 \%$ (12/215) which is comparable to Indian studies 5.7\% [17]. The neutrophils play integral part in defense mechanism against TB. This result was consistent with our study supporting the important role of neutrophils in the defense against TB infection. 
Table 2. Patient demographic characteristics (TB + AML cases).

\begin{tabular}{ccccc}
\hline Case No. & Age & Gender & Origin & Occupation \\
\hline 01 & 29 & Female & Ethiopian & Housemaid \\
02 & 39 & Female & Nepal & Non-skilled Worker \\
03 & 32 & Male & India & Construction labourer \\
04 & 6 & Male & Syria & Retired \\
05 & 24 & Male & Bangladesh & Skilled Worker \\
06 & 58 & Male & Philippines & Skilled Worker \\
07 & 45 & Male & India & Technical Worker \\
08 & 51 & Male & Philippines & Skilled Worker \\
09 & 26 & Male & Nepalese & Skilled Worker \\
10 & 30 & Male & Indian & Skilled Worker \\
11 & 42 & Female & Yemen & Housewife \\
12 & 30 & Male & Nepalese & Worker \\
\hline
\end{tabular}

Our study highlighted an important finding of significant delay in diagnosis of TB in patients with AML (mean 64.2 days, median 45 days). Ibrahim et al in a previous study from Qatar, reported mean and median total diagnostic delays of PTB among general population of 53 and 30 days, respectively [28].

In the present study, TB diagnosis was markedly delayed in Patient No. 1, 2, 3 and 9 due to confounding factors like bacterial and fungal infections that were concomitantly detected .Moreover the radiologic pattern was atypical. Patient no. 9 had fatal outcome due to co-infection with Candidiasis. In the remaining patients the challenge was regarding initiating anti-leukemia chemotherapy in active TB setting where drug-drug interactions and risk to the medical staff and other patients in the leukemia floor. Table 3 summarizes all details of diagnosis and results among the tested patients:

\section{Diagnosis}

The diagnosis of active PTB is a major challenge; such patients characteristically demonstrate an atypical radiographic pattern [22], like middle and lower lung lobes involvement, absence of cavity formation, presence of lymphadenopathy (LAD) and pleural effusion or miliary pattern [29]. The chest X-ray is usually normal because of attenuation of inflammatory signs by neutropenia. In the current study, 10 out of 12 patients had a normal chest X-ray. The CT-scan and MRI are the modalities of choice for the evaluation of specific body parts. CT is more sensitive than plain radiography in the detection and characterization of both parenchymal disease and mediastinal LAD [30].

In the current study, the most common radiologic findings were lung involvement in $83 \%$ of cases, mediastinal LAD $66 \%$ with central necrosis in $38 \%$ of these cases; hepato-splenic hypodense lesions in $33 \%$ and peritoneal involvement in 16\% (Tables 4-5; Figures 1-3). 
Table 3. Details of diagnosis and results among the tested patients.

\begin{tabular}{ccccccccc}
\hline $\begin{array}{c}\text { Total } \\
\text { no of } \\
\text { patients }\end{array}$ & $\begin{array}{c}\text { TB } \\
+\mathrm{ve}\end{array}$ & $\begin{array}{c}\text { Mean } \\
\text { Age }\end{array}$ & $\begin{array}{c}\text { APL } \\
+\mathrm{ve}\end{array}$ & $\begin{array}{c}\text { AML } \\
+\mathrm{ve}\end{array}$ & $\begin{array}{c}\text { Mean Delay in } \\
\text { diagnosis } \\
\text { (CI: 95\%) }\end{array}$ & $\begin{array}{c}\text { Median } \\
\text { (Interquartile range, } \\
\text { Q1 - Q3-29.5 - 97.5) }\end{array}$ & $\begin{array}{c}\text { Abnormality } \\
\text { observed }\end{array}$ & $\begin{array}{c}\text { Indication } \\
\text { (Death of patient) }\end{array}$ \\
\hline 215 & 12 & 39.8 & 3 & 9 & 64.2 days & 45 days & $\begin{array}{c}\text { Prolonged fever, } \\
\text { cough, parenchymal } \\
\text { lung involvement }\end{array}$ & $\begin{array}{l}\text { 01-Before treatment } \\
\text { 02-After treatment } \\
\text { 08-Completed treatment }\end{array}$ \\
\hline
\end{tabular}

Table 4. Clinico-radiological features.

\begin{tabular}{|c|c|c|}
\hline Patient No. & Clinical Presentation & Radiological findings \\
\hline 1 & $\begin{array}{l}\text { APL variant revealed by: } \\
\text { Fever } \\
\text { Weight loss (1 month or more) } \\
\text { Cough } \\
\text { Hemoptysis } \\
\text { Respiratory distress } \\
\text { Incubated } 7 \text { transferred to ICU }\end{array}$ & $\begin{array}{l}\text { Chest X-ray and US abdomen at admission: } \\
\text { Normal } \\
\text { CT scan at decompensation: } \\
\text { Mediastinal LN, pericardial, } \\
\text { pleural effusion, ascites, } \\
\text { Hepato-splenomegaly with hypodense lesions } \\
\text { peritoneal involvement. }\end{array}$ \\
\hline 2 & $\begin{array}{l}\text { APL variant revealed by: } \\
\text { fever with unknown origin, } \\
\text { persistence of fever during induction phase and after } \\
\text { neutropenia recovery }\end{array}$ & $\begin{array}{l}\text { Chest X-ray and US abdomen at admission: Normal } \\
\text { CT scan after neutropenia recovery: } \\
\text { left lower lobe basal fibrotic atelectasis band, } \\
\text { mediastinal and right hilar lymphadenopathy with central } \\
\text { necrosis }\end{array}$ \\
\hline 3 & $\begin{array}{l}\text { APL hypergranular subtype revealed by: Fever of } \\
\text { unknown origin for } 3 \text { months Abdominal pain } \\
\text { Anorexia } \\
\text { Weight loss }\end{array}$ & $\begin{array}{l}\text { Chest X-ray and US abdomen at admission: normal } \\
\text { CT scan after } 1 \text { week of APL treatment: mediastinal lymph nodes } \\
\text { and bilateral lung infiltrate suggestive of pulmonary edema } \\
2^{\text {nd }} \mathrm{CT} \text { scan after neutropenia recovery: Increase of mediastinal } \\
\text { lymph nodes size and hepatic hypodense lesions } \\
\text { MRI abdomen: suggestive of liver abscess } \\
3^{\text {rd }} \mathrm{CT} \text { scan and MRI during maintenance therapy: mediastinal } \\
\text { LN, minimal pleural effusion, hepatic abscess, peritoneal } \\
\text { thickening and nodules, ascites, mesenteric and omental } \\
\text { nodularity } \\
\text { PET CT scan: FDG avid uptake involving the whole abdomen } \\
\text { with absence of uptake in mediastinal LN }\end{array}$ \\
\hline 4 & $\begin{array}{l}\text { AML/MDS on palliative treatment: fever } \\
\text { Productive cough } \\
\text { Weight loss } \\
\text { Night sweat for } 2 \text { weeks }\end{array}$ & $\begin{array}{l}\text { - Chest X-ray: lung consolidation in the right upper and mid } \\
\text { lung zones } \\
\text { - CT-Scan: Consolidation } \\
\text { - } \quad \text { PET CT-Scan: bilateral lung consolidations and } \\
\text { peri-bronchial thickening, hilar and mesenteric LNs }\end{array}$ \\
\hline 5 & $\begin{array}{l}\text { AML with } t(8,21) \text { revealed by } \\
\text { Fever } \\
\text { Productive cough } \\
\text { Weight loss and anemia symptoms for } 2 \text { months }\end{array}$ & $\begin{array}{l}\text { - Chest X-ray at admission: Normal } \\
\text { CT-scan at admission; right and basal lung consolidation, } \\
\text { multiple lung nodules, mediastinal and intraperitoneal } \\
\text { lymph nodes some of them with central necrosis, } \\
\text { hepato-splengomy with hypo-dense lesion } \\
\text { PET-CT scan: multiple mediastinal LNs, left lung } \\
\text { consolidation, pulmonary nodules, retroperitoneal LN, } \\
\text { multiple liver lesions, left parotid gland uptake and D8 } \\
\text { vertebra uptake }\end{array}$ \\
\hline 6 & $\begin{array}{l}\text { AML with normal cytogenetic revealed by: } \\
\text { Fever } \\
\text { productive cough } \\
\text { weight loss } \\
\text { generalized LN for } 2 \text { months }\end{array}$ & $\begin{array}{l}\text { - Chest X-ray at admission: normal } \\
\text { - CT-Scan at admission: ground glass appearance in both } \\
\text { lungs, associated with pulmonary nodules, generalized LN } \\
\text { some of them with central necrosis }\end{array}$ \\
\hline
\end{tabular}




\section{Continued}

7 weight loss for 4 months

acute abdomen mimicking appendicitis 3 days before admission

AML with trisomy 13 revealed by:

Fever

8

night sweat

weight loss

cough

anemia symptoms

AML intermediate risk revealed by:

fever,

chills,

9 cough,

night sweats and weight loss for 4 weeks.

At day 4 of induction, he developed respiratory

distress, intubated and transferred to MICU.

10

11

Pulmonary tuberculosis and LN preceding the

diagnosis of AML by 4 months

AML intermediate risk revealed by:

Fever

Coughs

Dyspnea

12

hemoptysis

night sweats and weight loss $>1$ month.

Known to have TB 2 months before diagnosis of

AML. Not adequately treated.

- Chest X-ray: normal

- CT-scan of whole body: Lung nodule of the upper lobe of the left lung, atelectasis of the lower lobe, pleural effusion, hepatic lesion, thickening of the terminal ileum, mesenteric LN, and minimal pelvis free fluids

- Chest X-ray: normal

- CT scan: ground glass appearance in the right upper lung, mild bilateral pleural effusion with underlying relaxation collapse, mediastinal and retroperitoneal LN

- Chest X-ray: normal

- CT-scan: Mediastinal lymph nodes, absence of lung infiltration.

- Chest X-ray: normal

- CT scan: Lung nodule and mediastinal LNs

- Chest X-ray: normal

- CT scan of whole body before chemotherapy: mediastinal LN with central necrosis and lung fibrotic bands

- Chest X-ray: Lung consolidation

- CT scan: Multiple lung consolidations and infiltration, mild pleural effusion, multiple tiny nodulariies within both lungs. Axillary LN.

Table 5. Diagnosis: treatment and outcome.

\begin{tabular}{|c|c|c|c|c|c|}
\hline $\begin{array}{l}\text { Patient } \\
\text { number }\end{array}$ & Diagnosis & QuantiFERON & Organ involvement & $\begin{array}{l}\text { Associated } \\
\text { infection }\end{array}$ & Outcome \\
\hline 1 & $\begin{array}{l}\text { BAL: smear negative, } \\
\text { culture positive } \\
\text { PCR: M.T sensitive to } \\
\text { anti-TB }\end{array}$ & Negative & $\begin{array}{l}\text { Lung, pleura, LN, } \\
\text { pericardium, liver, } \\
\text { spleen abscess and } \\
\text { peritoneal nodule }\end{array}$ & $\begin{array}{c}\text { Pseudomonas } \\
\text { aeruginosa }\end{array}$ & $\begin{array}{l}\text { IMPROVED Sputum } \\
\text { culture: negative } \\
\text { (left country after } 2 \\
\text { months of treatment) }\end{array}$ \\
\hline 2 & $\begin{array}{l}\text { FNA and trucut biopsy of } \\
\text { mediastinal LN: } \\
\text { Pus: smear and culture } \\
\text { positive } \\
\text { PCR: MT } \\
\text { Biopsy: necrotizing } \\
\text { granulomatosis positive } \\
\text { for AFB }\end{array}$ & Negative & $\begin{array}{l}\text { Lung and mediastinal } \\
\qquad \text { LN }\end{array}$ & None & IMPROVED \\
\hline
\end{tabular}




\section{Continued}

3

4

5

6

8

Sputum: smear negative, culture negative

LN biopsy: necrotizing granuloma and AFB

BAL: MT

9

10

Sputum and BAL: negative

Sputum: smear and culture positive PCR: MT sensitive to anti-TB

PCR: MT sensitive to

anti-TB
Negative

Abdominal TB (LN, liver, peritoneum)

Lung and LN

None

Possible fungal

infection

Lung, LN, liver,

Positive salivary glands, bone, and bone morrow

None

Positive

Lung, $\mathrm{LN}$ and bone marrow

None

None

Positive

Lung, Ileum, liver, and LN

Lung and LN

None

Positive

Negative

Miliary TB

Lung and LN

None

C.glabrata and

C.Krusei in BAL

Positive

Positive

Lung and LN

PSA septicemia

Lung, pleural and LN (Miliary TB)
Positive
IMPROVED

IMPROVED

IMPROVED

IMPROVED

IMPROVED

Improved from TB. Died after $2^{\text {nd }}$ induction with systemic fungal infection (Trichosporon asheii)

Died 2 weeks after diagnosis of leukemia with ARDS and septic shock

IMPROVED on treatment.

\section{IMPROVED}

Died 3 weeks after diagnosis of leukemia with ARDS and septic shock 


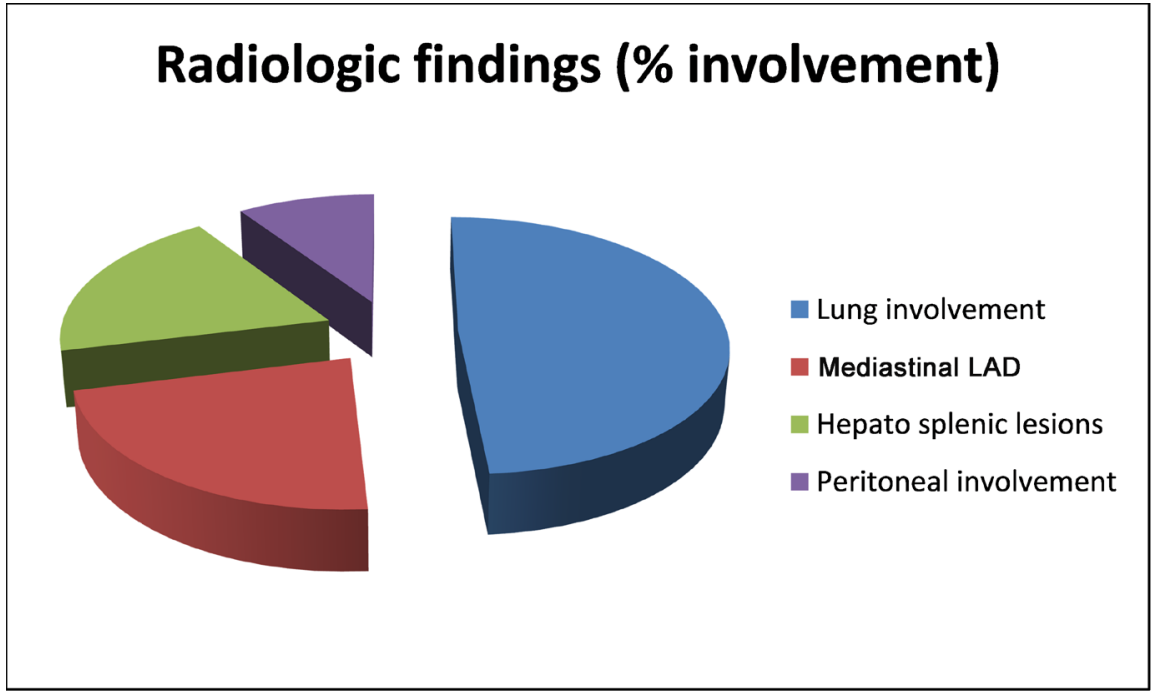

Figure 1. Radiologic findings (\% involvement).

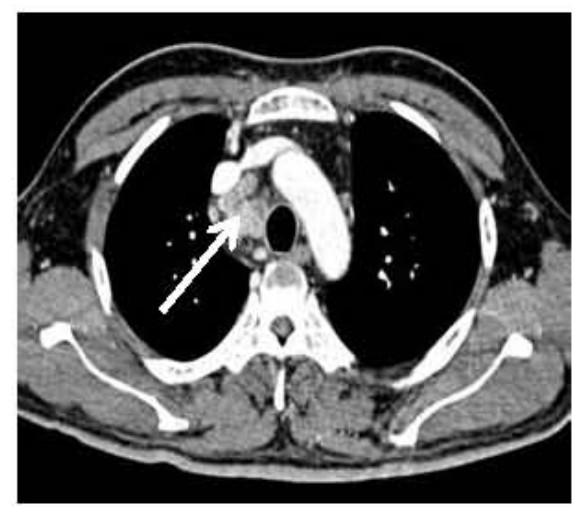

(a)

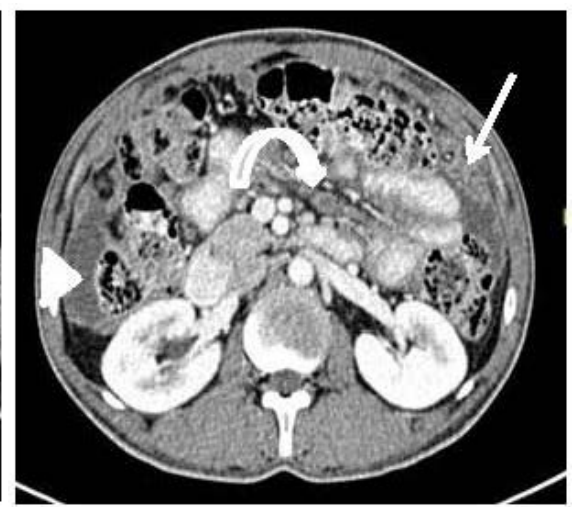

(b)

Figure 2. Patient 3. CT with intravenous contrast enhancement. (a) mediastinal paratracheal lymphadenopathy (arrow). (b) Omental thickening (arrow), ascites (arrow head), and mesenteric lymphadenopathy (curved arrow).

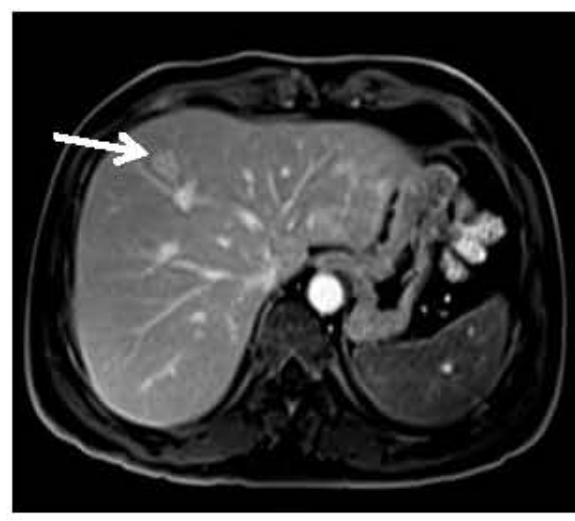

(a)

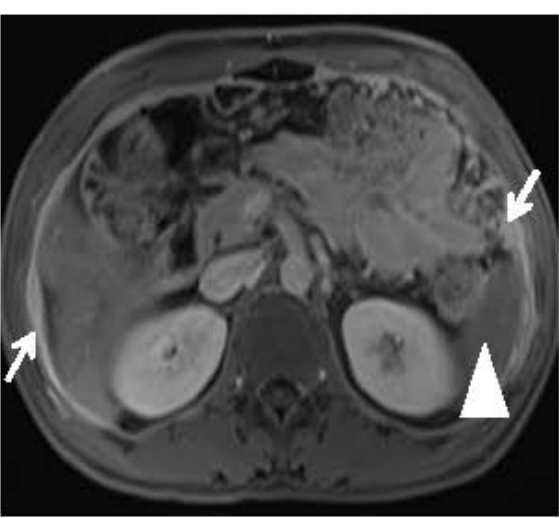

(b)

Figure 3. Patient 3. MRI of abdomen, contrast enhanced T1WI. (a) Focal enhancing lesion in the right hepatic lobe (arrow). (b) Thickened enhancing peritoneum (arrows), ascites (arrow head). 
$\left({ }^{18} \mathrm{~F}-\mathrm{FDG}\right)$ PET CT is a non-invasive tool capable of early detection of pulmonary and extra-pulmonary TB simultaneously with time and cost saving [29] [30] [31]. The indications of PET-CT in HM with TB are: 1) staging of TB 2) assessment of treatment response at 2 months, 3 ) guide the biopsy and lead to early diagnosis, and 4) distinction between old and active TB. In extra-pulmonary TB, ( ${ }^{18}$ F-FDG) PET-CT detects more TB lesions than CT. S. In our study, PET-CT scan was done in 4 patients for staging of TB disease. In patient 3 , it showed high uptake and multi-organ involvement in the abdomen and absence of uptake in mediastinal lymph nodes (LNs) supporting histopathology results. In the other patients it showed the spread of the disease (Figure 4).

Diagnosis of active TB relies on the detection of MT by culture or molecular biology techniques [32]. In our study, TB diagnosis was confirmed in nine cases, probable in two and possible in one. There were absence of resistance to anti-TB medications and such finding was reported in Abu Khattab et al. where low incidence of multi-drug resistant TB in Qatar was found $1.2 \%$.

We performed TB screening by Quantiferon ${ }^{\circledR}-\mathrm{TB}$ Gold In-Tube .This test has high sensitivity and specificity $75 \%$ and $81 \%$ respectively [33]. In our study it was reported positive in $67 \%$ of patients.

This is the first study to address the delay in diagnosis of TB and its clinico-radiologic findings among patients with AML in the State of Qatar; however the limitation of this study is the small number of AML patients diagnosed with $\mathrm{TB}$ and being a retrospective cohort.
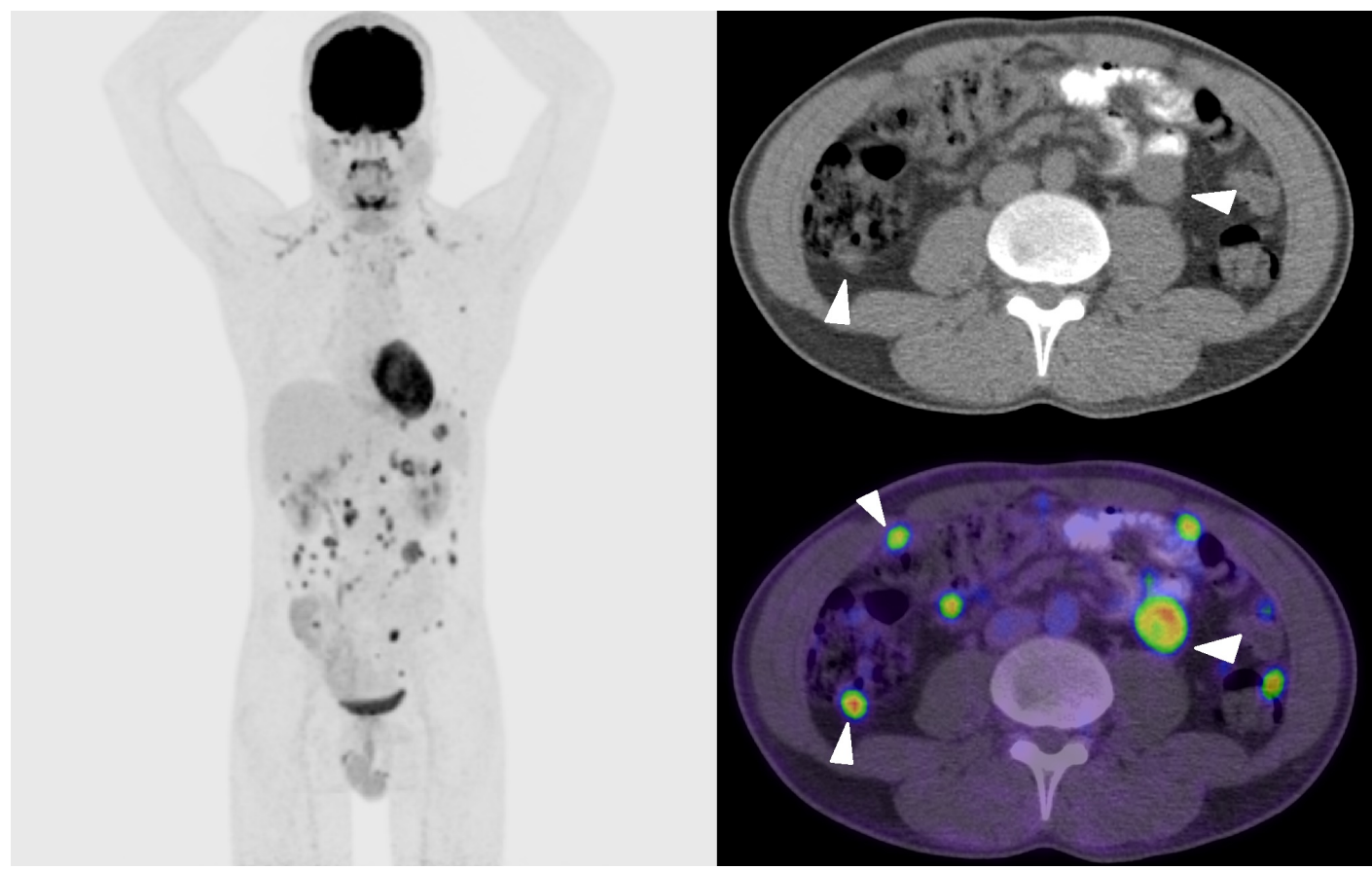

Figure 4. Patient 3. PET and CT images were collected with a Siemens mCT scanner 60 minutes after intravenous injection of 18F-FDG. Maximum intensity projection and transaxial CT and fused PET/CT images of the scan showing multiple mostly abdominal lesions. 


\section{Discussion}

The estimated prevalence of TB in AL varies between $3-4 / 1000$ new cases, in western countries [12] [13], to 22 - 69 per 1000 in India [14] [15] [16] [17]. Qatar has a highly effective National TB Program with one National TB Reference Laboratory that performs a full range of laboratory diagnosis and a case detection rate exceeding $70 \%$. The risk of developing TB varies and depends on the type of HM. Studies related to the same have shown significant variation. Silva et al reported in Brazil that out of more than 900 patients with HM; chronic lymphocytic leukemia (CLL) was the most sensitive disease to develop TB. The same study highlighted the role of CLL treatment with corticoids and fludarabine which increase the risk of developing TB [34]. However, Mishra et al. reported that patients with AML rather than lymphoma had a higher rate of MT disease [14]. Chen et al. [26] found that patients with AML in Thailand had significantly high incidence of TB than other sub-types of HM (2.87\% versus $1.21 \%)$. TB disease might be evaluated as an important differential diagnosis for patients with AML suffering from febrile neutropenia especially in a TB endemic area like our patients; however such correlation was not found in our ALL patients.

The diagnosis of active PTB highlights an atypical radiographic pattern. In our study, the most common radiologic findings, were lung involvement in $83 \%$ of cases, mediastinal LAD $66 \%$ with central necrosis in $38 \%$ of these cases; hepato-splenic hypodense lesions in 33\% and peritoneal involvement in $16 \%$. Chen et al. [26] found that most of their patients with HM and PTB had concomitant mediastinal LAD, pleural effusion, and fibro-calcified lesions. Andrew et al. reported that LAD is the most characteristic radiological feature in $T B$, in enhanced CT, hilar and mediastinal LAD with a central hypodense area supported the diagnosis [35].

The present investigation was demonstrated as retrospective cohort, which is the conducted for the first time in Qatar to analyze the delay in diagnosis as well as clinic-radiological features among patients of Qatar, belonging to different nationalities.

\section{Conclusion}

There is a significant delay in the diagnosis of TB among patients with AML as compared to general population, suggesting that TB in such patients may constitute a diagnostic challenge. our study illustrated that TB should be included in the extended clinico-radiologic differential diagnosis of febrile neutropenia and in patients with persistent fever after neutropenia recovesry even if fever is being explained by other reasons, particularly in regions with high prevalence of TB. We also highlighted the importance of screening for latent TB in patients with AML. Vigilance to this condition is of at most importance because of its implication on safety of the health care providers and other patients in the hematology floors. 


\section{Conflict of Interest}

The paper was approved by all co-authors; authors have no conflict of interest to disclose.

\section{References}

[1] World Health Organization. Global Tuberculosis Report 2012.

[2] Giovanni, D., Michela, S. and Giovanni, F. (2013) The Biology of Mycobacterium tuberculosis Infection. Mediterranean Journal of Hematology and Infectious Diseases, 5, e2013070.

[3] World Health Organization (2009) Global Tuberculosis Control: Surveillance, Planning and Financing. WHO/HTM/ TB/2009.411, WHO, Geneva.

[4] Dye, C., Scheele, S., Dolin, P., Pathania, V. and Raviglione, M.C. (1999) Consensus Statement. Global Burden of Tuberculosis: Estimated Incidence, Prevalence, and Mortality by Country. WHO Global Surveillance and Monitoring Project. JAMA, 282, 677-686. https://doi.org/10.1001/jama.282.7.677

[5] Wells, C.D., Cegielski, J.P., Nelson, L.J., et al. (2007) HIV Infection and Multidrug-Resistant Tuberculosis-The Perfec Storm. Journal of Infectious Diseases, 196, S86-S107. https://doi.org/10.1086/518665

[6] Al-Anazi, K., Aljasser, A. and Evans, D.A. (2007) Infections Caused by Mycobacterium tuberculosis in Patients with Hematological Disorders and in Recipients of Hematopoietic Stem Cell Transplant, a Twelve Year Retrospective Study. Annals of Clinical Microbiology and Antimicrobials, 6, 16.

https://doi.org/10.1186/1476-0711-6-16

[7] Zumla, A., Raviglione, M., Hafner, R. and von Reyn, C.F. (2013) Tuberculosis. The New England Journal of Medicine, 368, 745-755.

https://doi.org/10.1056/NEJMra1200894

[8] Fu, L.M. (2003) The Potential of Human Neutrophil Peptides in Tuberculosis Therapy. International Journal of Tuberculosis and Lung Disease, 7, 1027-1032.

[9] Martineau, A.R., Newton, S.M., Wilkinson, K.A., et al. (2007) Neutrophil-Mediated Innate Immune Resistance to Mycobacteria. Journal of Clinical Investigation, 117, 1988-1994. https://doi.org/10.1172/JCI31097

[10] Nauseef, W.M. and Borregaard, N. (2014) Neutrophils at Work. Nature Immunology, 15, 602-611. https://doi.org/10.1038/ni.2921

[11] Mayadas, T.N., Cullere, X. and Lowell, C.A. (2014) The Multifaceted Functions of Neutrophils. Annual Review of Pathology: Mechanisms of Disease, 9, 181-218. https://doi.org/10.1146/annurev-pathol-020712-164023

[12] Kaplan, M.H., Armstrong, D. and Rosen, P. (1974) Tuberculosis Complicating Neoplastic Disease. A Review of 201 Cases. Cancer, 33, 850-858. https://doi.org/10.1002/1097-0142(197403)33:3<850::AID-CNCR2820330334>3.0.C $\mathrm{O} ; 2-\mathrm{H}$

[13] Feld, R., Bodey, G.P. and Groschel, D. (1976) Mycobacteriosis in Patients with Malignant Disease. Archives of Internal Medicine, 136, 67-70. https://doi.org/10.1001/archinte.1976.03630010051009

[14] Mishra, P., Kumar, R., Mahapatra, M., et al. (2006) Tuberculosis in Acute Leukemia: A Clinico-Hematological Profile. Hematology, 11, 335-340. https://doi.org/10.1080/10245330600915818

[15] Gupta, A., Singh, M., Singh, H., et al. (2010) Infections in Acute Myeloid Leukemia: 
An Analysis of 382 Febrile Episodes. Medical Oncology, 27, 1037-1045. https://doi.org/10.1007/s12032-009-9330-9

[16] Advani, S.H. and Banavali, S.D. (1989) Pattern of Infection in Hematologic Malignancies: An Indian Experience. Reviews of Infectious Diseases, 11, S1621-S1628. https://doi.org/10.1093/clinids/11.Supplement_7.S1621

[17] Srivastava, V.M., Krishnaswami, H., Srivastava, A., Dennison, D. and Chandy, M. (1996) Infections in Haematological Malignancies: An Autopsy Study of 72 Cases. Transactions of the Royal Society of Tropical Medicine and Hygiene, 90, 406-408.

[18] Cardona, P.J. (2009) A Dynamic Reinfection Hypothesis of Latent Tuberculosis Infection. Infection, 37, 80-86. https://doi.org/10.1007/s15010-008-8087-y

[19] Barrios-Payán, J., Saqui-Salces, M., Jeyanathan, M., et al. (2012) Extrapulmonary Locations of Mycobacterium tuberculosis DNA during Latent Infection. Journal of Infectious Diseases, 206, 1194-1205. https://doi.org/10.1093/infdis/jis381

[20] Pai, M., Denkinger, C.M., Kik, S.V. et al. (2014) Gamma Interferon Release Assays for Detection of Mycobacterium tuberculosis Infection. Clinical Microbiology Reviews, 27, 3-20. https://doi.org/10.1128/CMR.00034-13

[21] Al-Suwaidi, Z. (2015) Tuberculosis in Qatar. International Journal of Mycobacteriology, 4, 124. https://doi.org/10.1016/j.ijmyco.2014.10.052

[22] Libshitz, H.I., Pannu, H.K., Elting, L.S. and Cooksley, C.D. (1997) Tuberculosis in Cancer Patients: An Update. Journal of Thoracic Imaging, 12, 41-46. https://doi.org/10.1097/00005382-199701000-00006

[23] de la Cámara, R., Martino, R., Granados, E., et al. (2000) Tuberculosis after Hematopoietic Stem Cell Transplantation: Incidence, Clinical Characteristics and Outcome. Bone Marrow Transplantation, 26, 291-298.

https://doi.org/10.1038/sj.bmt.1702506

[24] Kamboj, M. and Sepkowitz, K.A. (2006) The Risk of Tuberculosis in Patients with Cancer. Clinical Infectious Diseases, 42, 1592-1595.

[25] Stefan, D.C., Kruis, A.L., Schaaf, H.S. and Wessels, G. (2008) Tuberculosis in Oncology Patients. Annals of Tropical Paediatrics, 28, 111-116. https://doi.org/10.1179/146532808X302125

[26] Chen, C.Y., Sheng, W.H., Cheng, A., et al. (2011) Clinical Characteristics and Outcomes of Mycobacterium tuberculosis Disease in Adult Patients with Hematological Malignancies. BMC Infectious Diseases, 11, 324. https://doi.org/10.1186/1471-2334-11-324

[27] Wu, C.Y., Hu, H.Y., Pu, C.Y., et al. (2011) Aerodigestive Tract, Lung and Haematological Cancers Are Risk Factors for Tuberculosis: An 8-Year Population-Based Study. International Journal of Tuberculosis and Lung Disease, 15, 125-130.

[28] Ibrahim, W.H., Alousi, F.H., Al-Khal, A., Bener, A., AlSalman, A., Aamer, A., Khaled, A. and Raza, T. (2016) Diagnostic Delay among Adults with Pulmonary Tuberculosis in a High Gross Domestic Product per Capita Country: Reasons and Magnitude of the Problem. International Journal of Preventive Medicine, 7, 116. https://doi.org/10.4103/2008-7802.193091

[29] Vorster, M., Sathekge, M.M. and Bomanji, J. (2014) Advances in Imaging of Tuberculosis: The Role of 18F-FDG PET and PET/CT. Current Opinion in Pulmonary Medicine, 20, 287-293. https://doi.org/10.1097/MCP.0000000000000043

[30] Skoura, E., Zumla, A. and Bomanji, J. (2015) Imaging in Tuberculosis. International Journal of Infectious Diseases, 32, 87-93. https://doi.org/10.1016/j.ijid.2014.12.007 
[31] Omri, H.E., Hascs, I. Z., Taha, R., et al. (2015) Tubercular Meningitis and Lymphadenitis Mimicking a Relapse of Burkitt's Lymphoma on 18F-FDG-PET/CT: A Case Report. Case Reports in Oncology, 8, 226-232. https://doi.org/10.1159/000430768

[32] Anibarro, L. and Pena, A. (2014) Tuberculosis in Patients with Haematological Malignancies. Mediterranean Journal of Hematology and Infectious Diseases, 6, e2014026. https://doi.org/10.4084/mjhid.2014.026

[33] Kwon, J.C., Kim, S.H., Park, S.H., et al. (2013) Clinical Characteristics and the Usefulness of the QuantiFERON-TB Gold In-Tube test in Hematologic Patients with Hepatic or Splenic Lesions. The Korean Journal of Internal Medicine, 28, 187-196. https://doi.org/10.3904/kjim.2013.28.2.187

[34] Silva, F.A., Matos, J.O., de, Q.M.F.C. and Nucci, M. (2005) Risk Factors for and Attributable Mortality from Tuberculosis in Patients with Hematologic Malignancies. Haematologica, 90, 1110-1115.

[35] Andreu, J., Caceres, J., Pallisa, E. and Martinez-Rodriguez, M. (2004) Radiological Manifestations of Pulmonary Tuberculosis. European Journal of Radiology, 51, 139-149. https://doi.org/10.1016/j.ejrad.2004.03.009 